\title{
A EDUCAÇÃO DE JOVENS E ADULTOS E O PROGRAMA NOVA EJA: UM OLHAR ANALÍTICO SOBRE A CATEGORIA TRABALHO PARA FORMAR TRABALHADORES
}

\author{
Education of Youth and Adults and the Program New EJA: A Look on the Analytical Category \\ Work for Workers Form
}

\author{
Rodrigo Coutinho Andrade \\ Professor Assistente do Departamento de Educação e Sociedade - IM/UFRRJ \\ digocabeca@hotmail.com
}

Artigo recebido em 30/09/2014 e aceito para publicação em 23/01/2015

http://dx.doi.org/10.12957/tamoios.2014.13078

Resumo Em decorrência das mudanças materializadas pela SEEDUC-RJ após a penúltima colocação no Índice de Desenvolvimento da Educação básica, o programa Nova EJA constitui-se a medida, no bojo do "choque de gestão" empenhada pelo então secretário Wilson Risolia, para a educação de jovens e adultos. Prosseguindo o paradigma das reformas gerenciais do Estado para a educação pública, o mesmo reproduz as intencionalidades formativas de cunho neoliberal para o setor. Dentre as mutações, destaca-se a reformulação do currículo e do manual didático para a modalidade em questão; e, diante disto, a proposta do presente artigo é estabelecer olhares possíveis para o tratamento da categoria trabalho no/para o Ensino de Geografia, analisando concomitantemente o documento norteador para a efetivação do programa, o Currículo Mínimo e o manual didático, para tecer possíveis considerações em sua conclusão sobre a temática/conteúdo em questão.

Palavras-chave: Geografia, ensino, trabalho e EJA.

Abstract In view of the changes materialized by SEEDUC -RJ after the penultimate position in the Basic Education Development Index, the New EJA program is to measure, in the midst of "management shock " committed by the then Secretary Wilson Risolia, for the education youth and adults. Continuing the paradigm of state management reforms to public education, it reproduces the formative intentions of neoliberal for the sector. Among the changes, there is a reformulation of the curriculum and the teaching manual for the modality in question; and, before that, the purpose of this article is to establish possible looks for the treatment of work in the category for Geography Teaching concurrently analyzing the guiding document for the realization of the program, the Minimum Curriculum and instructional manual, to weave possible considerations in its conclusion on the subject/content in question.

Keywords: Geography, education, labour and EJA 


\section{INTRODUÇÃO}

O presente artigo objetiva-se a analisar, dentro de suas limitações, as mutações provocadas pelo programa Nova EJA no/para o ensino de Geografia, de acordo com sua estruturação políticopedagógica, tendo como prerrogativa a problematização da categoria trabalho no processo de ensinoaprendizagem na disciplina mencionada. Para isso, atentar-se-á às modificações produzidas pela Secretaria Estadual de Educação do Rio de Janeiro (SEEDUC-RJ) para a Educação de Jovens de Adultos, segundo seus objetivos explícitos e implícitos, concomitante a proposta curricular e o material didático utilizado como guia para o desenvolvimento das atividades pedagógicas; deixando claro desde já, que as práticas curriculares podem estar associadas, ou não, à reprodução unilateral dos recursos disponíveis pela secretaria mencionada, sendo impossível na atual proposição a sua mensuração, ou a aferição qualitativa dos resultados procedimentais do mesmo. Porém, é cada vez mais ampla e necessária para a regulação da prática docente, pela ótica do Estado-Auditor (Ball, 2004), a utilização das avaliações verticais, assim como seu refino, que pode ser questionada hipoteticamente como um mecanismo de controle para a atuação profissional-docente, assim como ao desenvolvimento das respectivas atividades didático-pedagógicas.

Consecutivamente, buscaremos traçar uma breve contextualização histórica, elencando possíveis fatos/fatores que legitimaram as transformações produzidas pela SEEDUC-RJ nos últimos anos, que resultaram também no programa em voga; para isso, analisaremos essencialmente o manual de orientações, que é apresentado enquanto ferramenta visceral para a apresentação e o desenvolvimento do curso pela secretaria estadual. $\mathrm{O}$ documento resultante, e aqui posteriormente em análise, estrutura-se enquanto guia analítico e metodológico para as finalidades explícitas, indissociável também para a compreensão das perspectivas formativas da/para a EJA no Estado do Rio de Janeiro, que divergem de relevantes leituras no âmbito acadêmico.

Após isto, o artigo propõe-se a articular as intenções descritas pelo documento norteador às orientações curriculares, seguidos para melhor compreensão e exemplificação, de uma breve análise do manual didático de Geografia destinado para a Terceira fase do Ensino Médio, objetivando a problematização das representações produzidas da categoria trabalho, assim como dos sujeitos-atores que vivem-do-trabalho (Antunes, 2005). Além disso, para melhor compreensão dos objetivos traçados, e elencados pelo programa, realizaremos uma breve leitura teórica sobre o currículo, principalmente em relação às perspectivas avaliativas e performáticas, como evidenciadas nas contínuas reformas gerenciais para a educação básica. Portanto, o debate sobre a categoria mencionada evidencia-se como o princípio norteador do artigo, vide a especificidade e identidade da modalidade Educação de Jovens e Adultos.

Para o diálogo com os possíveis paradoxos apresentados, tanto nos objetivos pedagógicos para a EJA, quanto para o ensino de Geografia, reproduziremos elementos conceituais da sociologia do trabalho, principalmente diante da formação escolar destinada historicamente para trabalhadores 
pertencentes às classes populares. Destarte, caberá apontar de maneira sintética e conclusiva, olhares específicos ao ensino de geografia na contemporaneidade, não recusando obviamente as particularidades da EJA, para desvelar com maior precisão as intencionalidades das reformas e inovações para a aprendizagem geográfica, e a reprodução dos discursos pedagógicos sob tal ótica, para as classes subalternas.

\section{BREVE CONTEXTUALIZAÇÃO HISTÓRICA DAS REFORMAS IMPLEMENTADAS PELA SEEDUC- RJ}

O programa em análise resulta do conjunto de reformas realizadas pela SEEDUC-RJ após o ano de 2009, em consequência imediata da penúltima colocação no ranking do Índice de Desenvolvimento da Educação Básica (IDEB). O mesmo insere-se no denominado "choque de gestão", como classificado pelo então secretário de educação do Estado do Rio de Janeiro Wilson Risolia, em entrevista ao jornal O Globo ${ }^{1}$ no dia 14 de agosto de 2012 . Tal termo especifica-se, pela ótica do secretário, em melhorar a qualidade da educação do estado em comparação as demais unidades federativas, o que salienta a prerrogativa performática ${ }^{2}$ como primeira hipótese, vide o ranqueamento como indicativo qualitativo.

Recontextualizando discursivamente modelos educacionais (Bernstein, 2003), diante de uma política internacional pautada por organismos supranacionais e multilaterais, que por motivos óbvios também ressoa(ra)m no território brasileiro, e em países em desenvolvimento, um conjunto de avaliações externas para os diferentes níveis dos sistemas educacionais tornou-se o modus operandi para o controle das medidas para maior eficácia dos investimentos públicos, de acordo com suas intencionalidades (Ciavatta; Rummert, 2010; Frigotto, 2010). Dentre elas, a Gestão Integrada da Escola (GIDE), produzida pelo governo do Estado do Rio de Janeiro, que encampa o plano de metas para a educação pública fluminense; indicando que, através do Planejamento Estratégico ${ }^{3}$, alcançaria os índices necessários para situar o Estado do Rio de Janeiro entre os primeiros no ranking nacional até o ano de 2014. Para tal, baseado no mesmo vértice das reformas gerenciais do Estado que ocorreram ao longo da década de 1990 no Brasil ${ }^{4}$, a GIDE enquanto política de gestão que tem como embrião o Sistema de Gestão Integrada, baseia-se no Índice de Formação de Cidadania e Responsabilidade Social do Rio de Janeiro (IFC/RJ), que oferece a escola possíveis diagnósticos para a obtenção de melhores resultados, segundo as ações esperadas pela secretaria para a ampliação de seu aproveitamento ${ }^{5}$. Dentre suas preocupações, destacam-se os resultados das avaliações — internas e externas a unidade escolar, assim como o índice fluxo escolar, convergindo ao discurso meritocrático — após a instituição/revisão da política de bonificação.

Para maior compreensão dos objetivos postulados pela secretaria, a resolução $n^{\circ} 4669 / 11$, publicada no Diário Oficial do Estado do Rio de Janeiro no dia sete de janeiro de 2011, também conhecida como a "cartilha da bonificação", orienta que 
para aferir as metas, a Secretaria de Educação criou o IDERJ (Índice da Educação Básica do Rio de Janeiro), que fornece um diagnóstico da escola em uma escala de zero a dez, baseando-se no Indicador de Desempenho (ID), medido através das notas do Saerj, e no Fluxo Escolar (IF). Além destes índices, também fará parte da meta de cada unidade escolar o IGE (Indicador Geral do Estado do Imóvel), elaborado pela Emop (Empresa de Obras Públicas) $[\ldots]$

Além de elevar os índices estipulados, para receberem a bonificação, os servidores lotados nas unidades escolares precisam cumprir $100 \%$ do currículo mínimo; participar de todas as avaliações internas e externas; efetuar o lançamento das notas dos alunos na forma e prazo estabelecidos; alcançar, no mínimo, 95\% de resultado em cada meta de IDERJ do ensino regular da unidade escolar; alcançar, no mínimo, $80 \%$ de resultado de cada meta de ID da Educação de Jovens e Adultos presencial da unidade escolar; e ter, pelo menos, $70 \%$ de frequência presencial no ano letivo. (GOVERNO DO ESTADO DO RIO DE JANEIRO, s/d(a), p. 4)

A resolução, e sua consecutiva execução, encontraram resistências por parte dos sujeitos que vivem o cotidiano escolar, representados principalmente pelo Sindicato Estadual dos Profissionais da Educação do Rio de Janeiro (SEPE-RJ), através de consecutivas greves e estratégias para a ampliação do debate com a comunidade escolar, como o acampamento em frente a sede da SEEDUC-RJ no ano de 2011. Ao mesmo tempo, a secretaria aprofundou suas ações através de programas diferenciados para a obtenção de melhores resultados, como a nova política de/para a Educação de Jovens e Adultos, voltada principalmente ao Ensino Médio. Também conhecido como Nova EJA, que como descrito pela resolução 4669/11, traria como uma das principais metas o mínimo de $80 \%$ no índice de desempenho conferível pelo SAERJ ${ }^{6}$, além da redução do mínimo presencial de $75 \%$ (como definido pela Lei de Diretrizes e Bases da Educação Nacional - 9394/96) para 70\%, de acordo com as especificidades da modalidade. Maiores considerações sobre a citação acima serão realizadas ao longo do artigo.

\section{NOVA EJA: OLHARES E ANÁLISES A SEUS OBJETIVOS E FINALIDADES}

Caberá no presente momento do artigo, a leitura do manual de orientações do programa, relacionado às suas expectativas e finalidades, integrado dialogicamente aos seus objetivos e procedimentos metodológicos, de acordo com as modificações estruturais e conjunturais produzidas pela SEEDUC-RJ, descritos de maneira introdutória no presente artigo. Para tal, buscaremos relacionar o documento em voga a considerações pertinentes a modalidade EJA, buscando maior 
compreensão do processo pedagógico para o mesmo, em ampla transformação.

Em parceria com a Fundação CECIERJ - Centro de Ciências e Educação Superior a Distância do Estado do Rio de Janeiro -, a SEEDUC-RJ inaugura o programa Nova EJA no ano de 2013, voltados principalmente para o Ensino Médio, respaldado pelo sexto parágrafo do décimo artigo da LDB 9394/96, de acordo com a prioridade referida aos Estados, atuando em regime de colaboração com os municípios para a garantia do Ensino Fundamental. No seu introito, o manual de orientações define as perspectivas do programa, como a busca

de consolidar uma escola de qualidade, conectada ao século XXI, capacitada para preparar os jovens e adultos para o mercado de trabalho, estimular o desenvolvimento de suas habilidades, constituindo no espaço escolar as condições propícias para conquista de sua autonomia e inserção nos diferentes e diversos espaços da vida social: exercício da cidadania plena, o trabalho, participação comunitária, atuação no cenário político (GOVERNO DO ESTADO DO RIO DE JANEIRO, 2013a, p.4).

Dentre as significativas afirmações, cabe distinguir especificamente dentre os objetivos, a capacitação dos jovens e adultos para o mercado de trabalho, em conjunto com o inexorável exercício da cidadania plena. $\mathrm{O}$ interesse por estas prerrogativas, e a ampliação dos indicadores, decorre também de pressões supranacionais (Frigotto; Ciavatta, 2003; Dale, 2004), garantindo a ampliação sustentável dos índices econômicos, orientando os projetos para a EJA na necessidade da inserção laboral de jovens excluídos (Souza, 2011, p.19), principalmente após o ano $2000^{7}$. Além disso, resta a hipótese sobre o papel da educação evidenciada na citação acima, que continua a ser pensada

como decorrência do perfil do novo trabalhador fabril, das metamorfoses do mundo do trabalho, da empregabilidade, de crise econômica, etc. O enfoque permanece da produção para a escola como se continuasse indiscutível a crença a crença em uma relação linear entre o mundo do trabalho, suas mudanças mais recentes e o mundo da escola e suas tímidas adaptações (ARROYO, 1999, p.18).

Analisar a naturalização dos discursos formativo-pedagógicos para o século XXI, vide o avanço técnico-tecnológico no qual alcança os mecanismos produtivos e sociológicos do capital nos dias atuais e, em plena expansão principalmente nas sociedades urbanizadas, significa - no olhar programático das políticas públicas contemporâneas - convergir às potencialidades pedagógicas para o (pseudo)domínio de saberes e conhecimentos ancorados às demandas produtivas, ou a inserção do corpo discente no mercado de trabalho. Portanto, ao direcionar para este fim os objetivos da escola 
para jovens e adultos, podemos reiterar a hipótese que o programa Nova EJA situa-se próximo das dimensões sociológicas, ou sociometabólicas do capitalismo pós-fordista (Alves, 2011), em convergência às diretrizes do capitalismo pós-moderno, pela/para materialização do trabalhador flexível (Harvey, 1993; Lojkine, 1995). Assevera-se isto por causa dos paradoxos das novas especificidades do/para o trabalhador contemporâneo, diante da ampliação da terciarização precária do mercado de trabalho, que compõe hoje aproximadamente $70 \%$ da composição do Produto Interno Bruto nacional (Pochmann, 2014, p. 31), e deriva por motivos óbvios, novas vicissitudes para a formação humana, diferenciadas do contexto econômico de predominância do pleno emprego, além da expansão da informalização das relações de trabalho.

Logo, o debate sobre a formação de jovens e adultos para o mercado de trabalho é merecedor de maior profundidade, para tornar mais complexo tamanha questão, que cristaliza-se assimetricamente nas políticas públicas voltadas para a educação das classes populares. Isto porque, segundo Sennett (2012), é cada vez mais comum a perda da identidade no trabalho executado, consecutiva a ampla flexibilização do trabalhador contemporâneo, além da amplitude tecnológica que reconfigura constantemente a relação capital-trabalho.

Esta concepção, que transformou-se no modelo hegemônico das políticas públicas voltadas para a educação, está eivada de intencionalidades implícitas. O primeiro sentido refere-se à omissão das condições estruturais do (mundo do) trabalho na contemporaneidade. Segundo Mattos (2011), Vasapollo (2005) e Pochmann (2012; 2014), o mercado de trabalho formal encontra-se altamente fragmentado e estratificado, demandando de maior qualificação e formação por parte do empregado, não o garantindo em momento nenhum a empregabilidade, no sentido histórico do pleno emprego. Como resultado, amplia-se por um lado o número de trabalhadores-estudantes ${ }^{8}$ nos cursos de pósgraduação e graduação, tomados ainda pelas incertezas laborais e sem identificações com atividades realizadas de maneira flexível (Sennett, 2012), subjugadas ao investimento imaterial do capital produtivo-humano ${ }^{9}$, e dotados em grande parte de salários asfixiados, e de outro a população à margem deste processo.

Em relação às classes populares e com baixa escolarização, a empregabilidade formal é ainda mais escassa ${ }^{10}$, devido ao acréscimo significativo do quantitativo excedente de mão-de-obra, principalmente em relação aos jovens recém-formados no ensino médio - o que provavelmente se agrava nos casos de formandos pelo curso de EJA, configurando para esta finalidade, uma certificação vazia de qualificação para o mercado de trabalho formal contemporâneo (Ciavatta; Rummert, 2010, p.463). Para este segmento da população, a relação exploratória capital-trabalho incide de maneira mais significativa, sustentado pelos estruturantes da modernização conservadora (Oliveira, 2013) à plena rotatividade nos postos de trabalho, alijados dos direitos conquistados ao longo dos anos, devido à menor resistência e organização coletiva, concomitante a desconstrução e arrocho salarial, onde a extração da mais-valia assegura-se na substituição do emprego pela ocupação temporária, acentuando os índices informais de trabalho, que torna-se um problema estrutural do/no capitalismo 
contemporâneo, reificando a superexploração da mão-de-obra através das flexibilizações e desregulamentações trabalhistas, combinados à condições periféricas históricas de relações de trabalho, complementares ao paradigma pós-fordista.

Concomitante as demandas do capital pós-fordista (Harvey, 1993; 2011; Lipietz; Leborgne, 1988), os novos valores do cidadão do século XXI, que vive do trabalho, abarcam subordinações naturalizadas pela nova morfologia da relação capital-trabalho (Alves, 2011), como a responsabilização, à meritocracia, à competitividade, à produtividade, ao empreendedorismo, e ao autoempresariamento (Rummert, idem). Para isto, se propaga ideologicamente, através da potencialidade, responsabilidade e "vontade" dos sujeitos, significantes reducionistas ao desenvolvimento cognitivo e profissional dos trabalhadores, e a sua consecutiva ascensão social e inserção no mercado de trabalho, logrando para a escola tal responsabilidade (Saviani, 1986). Ou seja, por meio de uma pedagogia centrada no indivíduo, oculta-se dimensões estruturais do capitalismo em crise (Mészáros, 2002), como a divisão social do trabalho, transferindo para os trabalhadores suas responsabilidades e desafios a superar através da aquisição de habilidades e competências, como descreve sequencialmente o manual de orientações.

Na ótica da evolução do ser, no desenvolvimento de suas potencialidades, é necessária uma metodologia que utilize estratégias de despertar e desenvolver nos jovens e adultos, habilidades e competências exigidas na sociedade e no mundo do trabalho (GOVERNO DO ESTADO DO RIO DE JANEIRO, 2013a, p.5).

O presente discurso pedagógico traz em seu arcabouço, através do "despertar", o resgate da teoria do Capital Humano, retornando as diretrizes da econômica neoclássica ${ }^{11}$ para a educação na contemporaneidade, de acordo com a necessidade de acúmulo permanente de conhecimentos específicos pelos sujeitos, para o exercício de atividades no mercado de trabalho, sendo classificados teoricamente enquanto capital humano. Ressignificando dessa forma o potencial formativopedagógico para as classes populares, o programa em análise retrata a categoria trabalho de maneira intencional-simplória, como um fim comum a todos os discentes. Acrescemos a isso que

o conceito de empregabilidade desloca a responsabilidade do desemprego da estrutura social e econômica para a pessoa que busca trabalho. Seu emprego depende unicamente de suas qualificações, isto é, de seu grau de empregabilidade. Mais do que uma simples noção, empregabilidade é uma forma de transformação da subjetividade, da identidade. (SILVA, 1999, p. 81)

Não se trata de apenas em afirmar a dualidade escolar em uma sociedade de classes 
antagônicas, pois como já descrito, a formação-qualificação para o mercado exerce suas particularidades, com intensidades diferentes, na totalidade social. Porém, tratando-se de uma modalidade que, voltada para sujeitos sociais excluídos por algum motivo da escolarização no período adequado, não tem como mencionar a particularidade politica da categoria, e do discurso nele embutido. Logo, o que se quer afirmar aqui é, que além da valorização do trabalho em sua dinâmica técnica e científica, existe indissociavelmente sua estruturante dimensão política (Santos, 2000, p.30), no qual a escola deve estar comprometida para a realização plena da natureza humana, recusando de imediato a falsa noção liberal de redenção dos injustiçados, ou como apenas um aparelho ideológico do Estado (Althusser, 1985).

Logo, como introdução as diretrizes do curso proposto a jovens e adultos, o manual de orientações exerce a função de explicitar os reais sentidos do processo de ensino-aprendizagem, alertando também as especificidades dos alunos em relação a suas experiências, tomado então como o protagonista para a construção do conhecimento. Portanto, valoriza-se o saber extra-escolar do alunotrabalhador, que em diálogo com o saber escolar produzirá sua reinserção ${ }^{12}$ (Governo do Estado do Rio de Janeiro, 2013a, p. 4) ao mundo do trabalho com escolarização adequada.

\section{O PROGRAMA NOVA EJA E SUA ESTRUTURAÇÃO METODOLÓGICA E CURRICULAR}

A matriz do curricular do programa para o Ensino Médio diferencia-se da Educação Básica, de acordo com a distribuição das disciplinas ao longo dos semestres e o tempo disponível para o desenvolvimento das atividades. Segundo o manual de orientações, o curso realiza-se em dois anos, fragmentados em quatro módulos, compondo dessa maneira a estrutura diferenciada dos anos/séries semestrais que anteriormente estavam em vigor.

Porém, a distribuição das disciplinas contém uma nova especificação ao longo dos módulos, havendo a constância apenas da Língua Portuguesa, Matemática e o Ensino Religioso. O ensino de Geografia acontece apenas no primeiro e no terceiro módulo, dispondo de quatro tempos semanais; cabe salientar que sua inclusão no material didático disponível para os alunos, pertence ao corpo amplo das Ciências Humanas ${ }^{13}$, em conjunto com a História, Filosofia e Sociologia - enquanto no Currículo Mínimo para a EJA o mesmo não ocorre.

Os procedimentos avaliativos não diferem das prerrogativas da Educação Básica que, fixados nos indicadores de desempenho, atribuem quatro parâmetros para a avaliação dos estudantes, citadas a seguir. Mas cabe destacar a inclusão da taxa de abandono por módulo, que influi diretamente na atuação da unidade escolar perante as metas definidas pela SEEDUC-RJ, como preceito para maior efetividade dos gastos com a área. Além do critério citado, que compõe o ID, a avaliação também inclui a taxa de conclusão, que também está relacionando à questão do abandono, o desempenho do aluno na avaliação diagnóstica bimestral (Saerjinho) e, por fim, seu desempenho no SAERJ (GOVERNO DO ESTADO DO RIO DE JANEIRO, 2013a, p. 13). 
Apesar de não apresentar considerações específicas sobre o processo avaliativo, os quatro movimentos que resumem a aprovação, ou reprovação, dos alunos estão restritos diretamente ao cotidiano escolar, pela ótica da SEEDUC, através do manual de orientações. Porém, o ID estrutura-se como forma de controle-regulação para o acompanhamento e avaliação do programa, ratificando o papel do Estado-auditor/regulador (Ball, 2010), tendo em vista a avaliação dos docentes e da escola diante de sua performance, através das avaliações verticais.

O Currículo Mínimo é apresentado em fases semestrais sequenciais, segundo a organização das disciplinas ao longo do Ensino Médio, destoando da matriz organizacional das disciplinas no Manual de Orientações. Nesse sentido, observa-se um paradoxo entre os conteúdos elencados e o momento propício para o desenvolvimento do mesmo ao longo do curso. Porém, em sua apresentação, o documento traz uma significativa contribuição, mesmo que de forma resumida, para a compreensão da ciência geográfica de maneira crítica. O mesmo afirma que

a Geografia é tratada numa perspectiva de uma ciência social cujo olhar se estende desde os atores sociais até os fenômenos naturais numa perspectiva espacial integrada e crítica. $\mathrm{O}$ ensino da Geografia cumpre importante papel no sentido de oportunizar aos jovens e adultos o acesso a conhecimentos e instrumentais que permitam o desvendar de atores e de processos socioespaciais com implicações diretas e indiretas em suas vidas, assim como dos mecanismos de ação política e intervenção na formulação de políticas públicas que tenham como objetivo a melhoria das condições de vida do conjunto da sociedade (GOVERNO DO ESTADO DO RIO DE JANEIRO, 2013b, p. 3).

Concordante às considerações realizadas acima, o texto apresenta em seu direcionamento o desvelo para questões salutares aos atores sociais, que por suas particularidades etárias e socioeconômicas, produzem com mais profundidade hipóteses significativas para o questionamento das contradições geográficas em nossa sociedade, principalmente quando atenta-se o olhar à totalidade, recusando em primeiro momento históricas fragmentações para a leitura e compreensão dos fenômenos socioespaciais. Considerar e materializar uma ciência, em que a pauta desenvolver-se-á pelo desvendar as oclusões postas pelo senso comum, ou pelas informações contidas nos meios de comunicação hegemônicos, é uma das principais contribuições da pedagogia crítica, que segundo Mészáros (2005, p.59), possibilita a "transcendência positiva da autoalienação do trabalho". Porém, alguns paradoxos a esta tese, muito já analisados pela ciência geográfica, se observa no corpo do currículo; ou melhor, na distribuição das habilidades e competências ao longo do documento para a Educação de Jovens e Adultos.

Em relação à disposição dos conteúdos no Ensino Fundamental, o Currículo Mínimo apresenta 
em suas competências e habilidades a mesma concepção persistente na Educação Regular, com abordagens conceituais e socioambientais no sexto ano, acompanhadas de uma leitura concêntricaescalar até o término do nono ano. Não observa-se na leitura do currículo uma diferença em relação a isto. Além disso, em relação ao Brasil que se ensina (Andrade; França Filho, 2013; Moreira, 1989), mais especificamente no sétimo ano, o Currículo Mínimo destinado a EJA é idêntico ao Ensino Fundamental regular, não superando a estrutura N-H-E (Moreira, op. cit.), com considerações as possíveis regionalizações do país de maneira introdutória e panorâmica ${ }^{14}$. Ou seja, apesar de trazer para o debate conteúdos de profunda relevância, como a diversidade sociocultural e econômica entre as regiões brasileiras, o mesmo reproduz estruturalmente a sequência de temas sob o arquétipo sequencial natureza $\rightarrow$ humano (entendido como população) $\rightarrow$ economia.

Para o desdobramento dos conteúdos no Ensino Médio para jovens e adultos, a formula se reproduz, repetindo de maneira resumida os temas desenvolvidos no Ensino Médio regular. Porém, como não cabe aqui uma leitura aprofundada sobre o documento, e ao mesmo tempo não é esse o objetivo do artigo, passaremos a observação da categoria trabalho, e como o mesmo é desenvolvido no Currículo Mínimo para a EJA.

O tema é proposto e consolidado como "foco" no primeiro bimestre do terceiro ano do Ensino Médio, intitulado como As transformações no processo de industrialização no mundo contemporâneo - o trabalhador, as tecnologias e a Globalização. Suas habilidades e competências são:

- Localizar as principais regiões industriais no mundo, relacionando as novas formas de organização dos espaços industriais à consolidação da economia em redes concentração/desconcentração industrial;

- Relacionar as mudanças na atividade industrial à expansão do setor terciário no mundo, identificando e analisando as transformações recentes no território brasileiro e fluminense;

- Identificar e comparar os fatores de localização industrial tradicionais e analisando as dinâmicas industriais no território brasileiro e fluminense.

- Caracterizar e comparar os paradigmas organizacionais e produtivos - fordismo e pós-fordismo -, relacionando à Revolução Técnico-Científica e observando as transformações socioespaciais no Brasil e no mundo.

- Relacionar as características da III Revolução Industrial à precarização das condições de trabalho - desemprego estrutural, flexibilização de leis trabalhistas, enfraquecimento dos sindicatos - com ênfase para as mudanças no mundo do trabalho no Brasil;

- Analisar propostas alternativas para enfrentamento dos problemas decorrentes da introdução de novas tecnologias no setor produtivo e na vida cotidiana, respeitando os valores humanos e a diversidade sociocultural. (GOVERNO DO ESTADO DO RIO DE JANEIRO, 2013b, p. 12).

Não cabe aqui uma consideração sobre todos os "pontos" destinados para a temática, considerada como foco, no primeiro bimestre do terceiro ano do Ensino Médio. Como o artigo 
pressupõe um olhar mais especifico a leitura da categoria trabalho, tanto em sua peculiaridade na proposta do programa, quanto no conteúdo geográfico, sinalizaremos uma análise mais apropriada aos quarto e quinto "pontos", principalmente no tocante ao tratamento oferecido pelo material didático do aluno a tais questões.

\section{A CATEGORIA TRABALHO NO MANUAL DIDÁTICO PARA O ALUNO DO PROGRAMA NOVA EJA: UM OLHAR SOBRE O DISCURSO GEOGRÁFICO}

$\mathrm{Na}$ introdução destacamos a recusa acerca da reprodução mimética dos manuais nas práticas curriculares, salientando até a impossibilidade de tal mensuração. Porém, alguns elementos nos sugerem um pouco de cuidado, tanto pela reprodução pura dos elementos didáticos produzidos pelas secretarias ou órgãos competentes ${ }^{15}$, quanto pela busca de materiais alternativos, ou a inutilização do mesmo. Ao mesmo tempo, cabe ressaltar que os autores do currículo orientam para a utilização de outros recursos didáticos, de muita valia para a produção do conhecimento geográfico.

Cabe ainda salientar que o livro didático ainda é utilizado sem a devida compreensão dos seus fundamentos teórico-metodológicos, como nos remete pesquisas realizadas pelos alunos nas disciplinas de estágio supervisionado, o que torna a questão sobre a sua compreensão, uso e avaliação ainda mais salutar para a formação de professores (Castellar; Vilhenha, 2011; Pontuschka et. al., 2007). Concomitante a isto, os livros avaliados pelo PNLD devem seguir as orientações curriculares estabelecidas pelos Parâmetros Curriculares Nacionais ( $\mathrm{PCN}^{\prime}$ s); e portanto, deduz-se que o mesmo deve ser realizado na esfera estadual; ou seja, que dialogue com as perspectivas salientadas do/no Currículo Mínimo.

Contudo, um dos elementos que deve ser analisado aqui, no bojo da questão avaliativa e performática do ensino após as reformas gerenciais, refere-se ao controle exercido pelas verificações consideradas diagnósticas, que neste caso são o SAERJ e o Saerjinho. Ambos são entes estruturantes do ID para a SEEDUC-RJ e, portanto, podem ser classificados como instrumentos reguladores do ensino na rede estadual do Rio de Janeiro; e por isso, podem ser considerados enquanto elementos que quantificam o desenvolvimento cognitivo e intelectual dos alunos, de acordo com as diretrizes dos órgãos responsáveis. Portanto, podemos alçar hipoteticamente que os docentes que almejam o alcance das metas, que indissociavelmente está atrelado ao resultado nas avaliações verticais, como orienta a resolução 4669/11, tendem a seguir as recomendações curriculares e didáticas, pois os conteúdos dispostos nas provas bimestrais e anuais não fogem ao rol de temas e conceitos estabelecidos no/pelo material didático produzido, assim como em seu caráter teórico-metodológico.

Feito esta consideração, analisaremos a primeira unidade do módulo três do livro referência para o Programa Nova EJA ${ }^{16}$. O mesmo, sob o título $A$ indústria e seus diferentes processos de organização espacial (Governo do Estado do Rio de Janeiro, s/d(b), p.5) apresenta uma linguagem apropriada para o público destinado, exemplificando introdutoriamente o processo histórico-produtivo 
até o período atual. Em concomitância com expectativa introdutória do Currículo Mínimo, espera-se que o manual abarque principalmente o desvendar de atores e de processos socioespaciais, no tocante ao processo produtivo.

No primeiro momento, o subcapítulo “do que a indústria precisa?” (idem, p. 7), lista os instrumentos, fatores e elementos necessários para que a atividade produtiva aconteça. Em relação ao trabalhador, o mesmo destaca que "devem ser contratados funcionários assalariados (alguns qualificados, outros não, que realizam as tarefas mais simples e de menor remuneração) que vão atuar nas empresas de diversas formas" (op. cit., loc. cit.). Ademais, nada é explicitamente ressaltado em relação à categoria trabalho e aos que vivem-do-trabalho, sem problematizar de início o uso do mesmo, tratado adiante de maneira pontual nas "revoluções industriais".

O segundo aspecto que cabe a reprodução, assim como posterior análise, refere-se a denominada Segunda Revolução Industrial, que de maneira resumida destaca algumas transformações produzidas pelo paradigma produtivo taylorista-fordista. Em relação a caracterização do trabalhador o manual destaca que

o funcionário vai realizar apenas uma tarefa (por exemplo, passar o dia parafusando uma peça do automóvel a outra), durante longas horas de trabalho estafante e repetitivo. Há aqui uma clara divisão do trabalho. Cada um executa um "serviço" específico, para, no final da esteira, estar o automóvel pronto para ser transportado e vendido (GOVERNO DO ESTADO DO RIO DE JANERO, s/d(b), p. 10)

Mais adiante elucubra considerações sobre o cidadão inserido em tal lógica, em que para o mesmo adquirir um bem de consumo,

é necessário que ele tenha emprego e salário. Se este trabalhador for mais eficiente e produzir mais, seu salário aumentará e, assim, ele poderá consumir mais, movimentando a economia e aumentando os lucros e a geração de novos empregos e o recolhimento de impostos por parte dos governos. Não é uma boa ideia? É isso que chamamos de Taylorismo, criado por Taylor, que aperfeiçoou o que a Ford havia criado (op. cit., loc. cit.).

Explicitando considerações sobre a transição entre a segunda revolução industrial e o período denominado de Toyotismo - terceira revolução industrial -, o conteúdo descrito pelo manual continua tecendo descrições sobre a categoria aqui em análise, principalmente em relação as mutações no trabalho, e na vida do trabalhador.

O que fizeram os japoneses? Criaram um sistema de trabalho chamado de 
produção flexível. Com isso, os trabalhadores atuavam em equipes chamadas de células de trabalho e tomavam decisões mais rápidas. Por exemplo, se uma máquina quebrava, ou eles logo a consertavam, pois eles eram preparados e realizavam várias funções, ou acionavam o setor especializado, que rapidamente se deslocava para o conserto. Outra modificação importante foi a quase total eliminação de estoques. As empresas mantinham na fábrica apenas o que seria utilizado para aquele dia (just in time).Em vez de comprar grandes quantidades de peças e equipamentos, a fábrica adquiria apenas o necessário para a sua produção diária, ocasionando a diminuição dos custos e o aumento da produtividade. Para agilizar a produção, foram eliminados uma série de cargos intermediários, diminuindo os graus hierárquicos, o que aumentou a velocidade da tomada de decisões. Tudo isso com o intuito de aumentar o lucro. Foi uma pequena revolução copiada por muitas empresas ao redor do mundo (op. cit, p. 11).

As citações extraídas do livro didático dão o tom dos conteúdos expostos no manual brevemente analisado. E como objetivado enquanto vértice do presente texto, sequenciaremos analisando os conteúdos expostos, de acordo com a categoria trabalho. Sobre a diferenciação entre conceito e categoria, e a definição da última, entendemos que

O conceito vem basicamente de nossa relação lógica - intelectiva - com o mundo, num ato de racionalização dos dados sensíveis. Todo conceito tem de um lado forte ligação com os princípios lógicos que o norteiam e de outro com a categoria através da qual intervêm. [...] E as categorias são os conceitos vistos na ação prática de transformar os dados da experiência sensível em teoria. [...] a categoria é o conceito em ação. (MOREIRA, 2010, p. 108).

Desse modo, a categoria tende a gerar significado a um discurso epistemológico, de acordo com a ação prática, ou a experiência sensível-abstrata dos sujeitos sociais; e por isso, tende a pertencer neste caso, a um específico discurso - ou até homilia - para a representação do mundo material, eivado por motivos parciais - recusa-se aqui a neutralidade - de significações. Dito isto, cabe compreender como a representação categórica do mundo do trabalho, através de sua apreciação no manual didático, e concomitantemente o discurso nele implícito, produz um discurso paradoxal aos que vivem-dotrabalho, a guisa de conclusão. 


\section{CONSIDERAÇÕES FINAIS}

Abarcando analiticamente as citações do manual didático, o processo conclusivo do artigo tensionará para a análise dos textos extraídos, e o diálogo posterior do mesmo com o Currículo Mínimo, para enfim, estabelecer possíveis considerações e olhares a proposta da presente escrita. Desde já estabelecemos como prerrogativa ímpar a finalidade hipotética do artigo, ensejando um olhar possível sobre as políticas públicas para a Educação de Jovens e Adultos e o conteúdo geográfico para as finalidades formativas.

Em relação a primeira citação extraída do manual didático, relativo ao subcapítulo "do que indústria precisa?", a categoria trabalho, materializada pelo sujeito que vive-do-trabalho é concebida enquanto ente estruturante do processo produtivo, como uma das peças-chave para o desenvolvimento da atividade econômica, por motivos óbvios. Porém, definido de maneira breve, sem possibilidade de maior problematização, atentamos a duas análises sobre esta caracterização.

No primeiro momento podemos afirmar que o mesmo é significado enquanto mercadoria variante de acordo com a qualificação, atuando diferentemente segundo a divisão social do trabalho. Contratado e assalariado, o trabalhador é representado essencialmente, e dentro de uma relação social pré-estabelecida entre homens, como a "forma fantasmagórica de uma relação entre coisas" (Marx, 1999, p. 94). Além disso,

as relações sociais entre seus trabalhos privados aparecem de acordo como realmente são, como relações materiais entre pessoas e relações sociais entre coisas, e não como relações sociais diretas entre indivíduos e seus trabalhos (op. cit., p. 95).

Cabe destacar a forma coisificada no qual a relação entre os trabalhadores e o processo produtivo é estabelecido na introdução ao conteúdo, pois visto como elemento componente da indústria, fora da relação específica ao valor de uso do trabalho, acenando apenas à relação contratação-assalariamento; ou seja, estruturalmente como o dispêndio fisiológico de trabalho para a criação de valor. Reifica-se o discurso de maneira sequencial a sua relação com a indissociabilidade qualificação-assalariamento, justificando o discurso contemporâneo para as dimensões formativas em vistas às demandas do capital, de maneira simples. Ou seja, enquanto proprietário de sua força de trabalho, é inexorável à sua existência a mercadorização do mesmo, em troca de meios subsistenciais de maneira fragmentada - segundo sua qualificação-valor.

De outro modo, a citação inicial oculta as contradições sociais do valor do trabalho, definidores instituintes da sociedade de classes, através da atribuição valorativa a funcionalidade do trabalhador no processo produtivo. Quando relega a menor remuneração a baixa qualificação, específica a divisão social do trabalho, legitima pelo viés da valorização do trabalho qualificado, a fragmentação da força de trabalho. Dessa maneira, atrela-se ao conceito de capital humano, aqui 
brevemente analisado, a relação entre trabalho e valor, específico também para a constituição da sociedade de classes.

Sobre a evolução histórica, geográfica e técnica da produção industrial, cabe considerar que o manual segue suas considerações de maneira linear, explicitando apenas o processo transitório entre as "revoluções industriais". Destarte, recusa a compreensão, através pontualidade descritiva, das persistências de paradigmas produtivos pretéritos na contemporaneidade, como exemplo primário. Tal descrição sequencial não permite, de certo modo, a combinação entre diferentes padrões produtivos como breve exemplo.

Acerca da categoria trabalho no período da "segunda revolução industrial", sua exemplificação não foge as considerações corriqueiras dos livros didáticos para a Educação Básica, acentuando principalmente o caráter repetitivo do processo de trabalho. Elemento crucial para a produção em massa, o mesmo demarca segundo Harvey (1993), o instrumento refinado da administração científica para a produção, destinado também a outras atividades contidas para a circulação e consumo das mercadorias. Porém, cabe ressaltar aqui, de acordo com as necessárias problematizações em evidência para os atores sociais, que a administração mencionada propositou mutações específicas, de acordo com o nova morfologia do trabalho no período em questão.

O Primeiro ponto que consideraremos atrela-se a condição estabelecida pelo fordismotaylorismo em produzir a "grande indústria" (Alves, 2011), constituindo a racionalidade produtiva de caráter coletivo, adquirindo com isso uma nova conjuntura, com a combinação de elementos cruciais para tal. Para a classe trabalhadora, que nesse período caracterizava-se enquanto unifuncional, era imprescindível uma nova psicologia do trabalho, atrelada a uma nova ética do trabalho. Dentre elas a combinação de "questões de sexualidade, de família, de formas de coerção moral, de consumismo e de ação do Estado" (Harvey, 1993, p. 122), instituintes a formação humana do/para o século XX, estabelecidas até no controle dos seus hábitos cotidianos, como em 1916, quando Ford

enviou um exército de assistentes sociais aos lares dos seus trabalhadores "privilegiados" (em larga medida imigrantes) para ter certeza que o "novo homem" da produção de massa tinha o tipo certo de probidade moral, de vida familiar e de capacidade de consumo prudente (isto é, não alcoólico) e "racional" para corresponder às necessidades e expectativas da corporação (Op. cit., loc. cit.).

Cabe a isso esclarecer que a mão-de-obra, ou melhor, o "funcionário" fordista era em grande parte constituída de migrantes "privilegiados", com ampla rotatividade, como nos explica o autor supracitado. $\mathrm{O}$ mesmo reitera sobre a hostilidade à rotina e exploração implementada na relação capital-trabalho no período fordista, como o caso enfrentado em sua expansão para os países europeus, e ao mesmo tempo a caracterização da própria recusa dos norte-americanos em relação à submissão ao 
padrão produtivo.

Portanto, o discurso em que consiste a caracterização do trabalho no período fordista-taylorista alça a hipótese de possível naturalização das contradições, ou oclusão da mesma. Além disso, para a análise dialética da categoria em questão, advém a necessidade de expor as contradições em voga no período descrito, que podem potencializar reflexões importantes na contemporaneidade, principalmente em relação ao papel do Estado de bem-estar social, que no período

aguentava a carga de um crescente descontentamento, que às vezes culminava em desordens civis por parte dos excluídos. No mínimo, o Estado tinha de tentar garantir alguma espécie de salário social adequados para ou engajar-se em políticas redistributivas ou ações legais que remediassem ativamente as desigualdades, combatessem o relativo empobrecimento e a exclusão das minorias (HARVEY, 1993, p. 133).

Soma-se a isto os trabalhadores do Terceiro Mundo, insatisfeitos

com um processo de modernização que prometia o desenvolvimento, emancipação das necessidades e plena integração ao fordismo, mas que, na prática, promovia a destruição de culturas locais, muita opressão e numerosas formas de domínio capitalista em troca de ganhos bastante pífios em termos de padrão de vida e de serviços públicos (por exemplo, no campo da saúde), a não ser para uma elite nacional muito afluente que decidira colaborar ativamente com o capital internacional (Op. cit., loc. cit.)

Logo, homogeneizar através da categoria trabalho, em relação a simplificação de sua caracterização monofuncional, a identificação geográfica em conjunto a linearidade histórica, positivado o ideário taylorista, mencionado como uma boa ideia, pode ascender aqui, um discurso demasiadamente simples e intencional para estudantes-trabalhadores pertencentes às classes populares. Acreditamos que a positivação da ética capitalista se faz presente nos discursos ensejados pelo manual didático, tendo como epicentro para tal, a categoria em questão, mesmo diante de latentes contradições.

Continuando, a análise do manual didático destinado ao Programa Nova EJA, que sequencia o conteúdo discriminado através da descrição da "terceira revolução industrial”, realiza uma exposição sobre o toyotismo através das inovações realizadas pelos japoneses, classificado como produção flexível. A descrição evolui comentando as novas perspectivas para o trabalho, ressaltando as células e a rapidez nas soluções necessárias, em antagonismo ao fordismo-taylorismo. Como identificação do processo produtivo, o instrumento didático menciona a eliminação dos estoques, através do paradigma just in time. Sem problematizar muito, legitimando através da ampliação do lucro, a mesma explicita a 
eliminação de cargos intermediários, assim como a amplitude técnica.

Reiteramos que, que para o tratamento da categoria trabalho, a flexibilidade tornou-se a classificação comum, concomitante às demandas corporativas. Por tratar-se do processo produtivo e laboral em destaque para a contemporaneidade, deveria expandir-se para temáticas mais próximas dos alunos, principalmente em relação ao próprio termo flexibilidade, que está além do exercício laborativo. Sobre a nova morfologia do trabalho, acredita-se que algumas considerações deveriam ser elencadas, para a compreensão e diálogo de um geografia para os atores sociais.

No primeiro momento, o artigo converge a análise de Giovanni Alves (2011, p.62), onde o "aspecto original do toyotismo é articular a continuidade da racionalização do trabalho, intrínseca ao taylorismo e ao fordismo, com as novas necessidades da acumulação capitalista numa etapa de crise de superprodução". Logo, observa-se a necessidade de releitura da descontinuidade entre as "revoluções". De outro modo, alegamos que o trabalho em si sofre-u novas vicissitudes em relação ao trabalho-vivo, mas o que de fato consta-se está envolto as novas formas de controle material e subjetivo no processo de produção capitalista.

Logo, realizar uma análise sobre o trabalho, e obviamente aos sujeitos que vivem-do-trabalho, requer assinalar que as morfologias estão assentadas na reinvenção das formas de subsunção do trabalho ao capital. Dentre tais, cabe assinalar que a classificação flexível, como já mencionada, reside a ampliação da exploração na relação capital-trabalho, através do termo racionalidade cínica ${ }^{17}$. Ademais, cabe ressaltar que tais contradições, advindas do sobreuso do termo flexibilidade, adentra também a novos termos, e portanto, a novas transformações. Dentre elas, a necessidade do espírito do toyotismo, que "irá impulsionar na linguagem do managering, os apelos à administração participativa e ao "gerenciamento pós-moderno" [...] agora, são os valores dos colaboradores, suas crenças, sua interioridade, sua personalidade que serão cobiçadas" (Alves, 2011, p. 65).

Portanto, tratar do trabalho na contemporaneidade não caberia apenas remeter-se a sua funcionalidade no processo produtivo. Se estamos dispostos a oferecer instrumentos para os discentes, cabe ir além de suas funcionalidades na engrenagem do capital. E observar os novos dispositivos para a regulação dos que vivem-do-trabalho, requer atentar para as novas especificidades da atividade produtiva - dentre elas o termo flexibilidade. Além disso, a própria desespecialização atribui um novo patamar de desintegração da classe-que-vive-do-trabalho, vide "o ataque ao saber profissional dos operários qualificados, a fim de diminuir seu poder de produção e aumentar a intensidade do trabalho" (Antunes, 2011, p. 57), que obviamente refletiu em seu poder de negociação e atuação sindical, com a ascensão do trabalho imaterial-morto, concomitante a segmentação da classe trabalhadora.

Além disto, ao homogeneizar o trabalhador, e consecutivamente o trabalho, os recursos discursivo do manual didático desconsidera algumas peculiaridades salutares a presente análise. De acordo com a caracterização multiforme e contraditória, observamos como possível contribuição, a consideração de que a categoria trabalho deveria abarcar esta prerrogativa, contra sua homogeneização. Nesse sentido, tanto em relação a sua constituição subjetiva, cabe salientar que a 
mesma é altamente polimórfica em relação aos sujeitos. Portanto, diante de tal complexificação, atribui-se a mesma, a significação voltada para o olhar das classes que vivem na periferia da força de trabalho, que compreende

dois subgrupos diferenciados: o primeiro consiste em "empregados em tempo integral com habilidades facilmente disponíveis no mercado de trabalho, como pessoal do setor financeiro, secretárias, pessoal das áreas de trabalho rotineiro e de trabalho manual menos especializado. Esse subgrupo tende a se caracterizar por uma alta rotatividade no trabalho. $\mathrm{O}$ segundo grupo situado na periferia oferece uma flexibilidade numérica ainda maior e inclui empregados em tempo parcial, empregados casuais, pessoal com subsídio público, tendo ainda menos segurança de emprego do que o primeiro grupo (HARVEY, 1993, p. 144 apud ANTUNES, 2011, p. 58).

Portanto, observamos que ao mesmo tempo em que o intensifica-se o discurso para a qualificação do trabalho, aprofunda-se o processo de desqualificação do mesmo. Logo, acenar para um viés apenas é paradoxal. E além disso, afirmar a categorização do mesmo com olhar sobre a formalidade empregatícia, exclui a complexidade sobre a subproletarização, que intensifica-se nos dias atuais (Antunes, idem). E por fim, cabe compreender que a análise da categoria trabalho, além da leitura sobre as especificações classistas, também compreende que para analisar

a classe trabalhadora hoje significa perceber também o significativo processo de feminização do trabalho, que atinge mais de $40 \%$ ou $50 \%$ da força de trabalho em diversos países, e que tem sido absorvido pelo capital, preferencialmente no universo do trabalho part-time, precarizado e desregulamentado (ANTUNES, 2005, p. 61).

É cabível pontuar que as afirmações estabelecidas na introdução ao Currículo Mínimo não ressoam no manual didático aqui analisado, e por isso, afirmamos que é observável um paradoxo entre os objetivos estipulados para a ciência geográfica e o discurso produzido, após análise do livro. Além disso, o mesmo insere-se no rol de materiais que pouco especifica a categoria aqui potencialmente problematizada, além de outros conceitos específicos da ciência geográfica.

Enfim, ao artigo pela sua estruturação, coube um olhar analítico sobre os conteúdos discriminados no manual didático e a concomitância ao documento curricular estipulado pela SEEDUC-RJ. E por isso limitou-se a alguns aspectos sobre a categoria trabalho, analisado de maneira sintética. Não se pretendeu aqui a desqualificação de qualquer documento, mas apenas a necessidade 
de aprofundamento de um tema tão relevante para os alunos-trabalhadores, oriundos em sua grande maioria das classes sociais menos abastadas. Logo, acredita-se na presente análise que ambos os materiais representam, mesmo que de maneira divergente, discursos sobre a formação na EJA, assim como sobre a geografia que se ensina, dentro de uma ótica específica. Portanto, espera-se que a presente leitura auxilie para o desenvolvimento do tema.

\section{NOTAS}

1 - Acesso realizado em 07 de junho de 2014, no site globo.globo.com/sociedade/educacao/estado-do-rio-pulado-penultimo-lugar-para-15-no-ideb-5788508.

2 - O termo utilizado converge com as mutações das políticas públicas para a educação, analisadas por Ball (2010), onde o Estado passaria a ampliar suas vicissitudes reguladoras, em contraposição ao então Estadoprovedor. O princípio propositivo ancora-se principalmente na centralização das avaliações verticais quantitativas, ou diagnósticas -, para a mensuração e controle da efetividade dos investimentos em sua finalidade. O mesmo acarretaria consecutivamente a "instauração de uma nova cultura de performatividade competitiva" (Ball, op. cit., p. 1107).

3 - Documento disponível no site http://download.rj.gov.br/documentos/10112/553225/DLFE37303.pdf/PlanejamentoEstrategico.pdf

4 - Segundo Bresser-Pereira (1996) e Friedman (1985), o Estado-gerencial passaria, através de mecanismos centralizadores e reguladores, inspirados na meritocracia, destinar novos objetivos e finalidades de inspiração (neo)liberal para a educação pública, materializando nos discursos qualitativos, a necessidade de aferição dos resultados e a constante avaliação do processo pedagógico, para maior controle da gestão do Estado, principalmente após a crise do capitalismo neoliberal na década mencionada, que orientou significativamente o papel da educação pública para a contemplação dos anseios economicistas (Paro, 2002).

5 - http://download.rj.gov.br/documentos/10112/553225/DLFE-37306.pdf/InformativoGIDE.pdf

6 - Segundo a resolução de $\mathrm{n}^{\circ}$ 5131, de 25 de julho de 2014, o SAERJ volta-se a aferição dos resultados, de caráter diagnóstico apenas no final de cada ano. O acompanhamento bimestral é realizado pelo Saerjinho, contemplando todas as disciplinas regulares dos diferenciados ano, enquanto o SAERJ ocorre no final do ano letivo, orientado pelas matrizes do Sistema de Avaliação da Educação Básica (SAEB), e somente para os anos concluintes. Logo, na avaliação bimestral, a finalidade controladora está no cumprimento do Currículo Mínimo, diante das Habilidades e Competências, restritos aos objetivos estabelecidos pela SEEDUC-RJ. Enquanto a avaliação vertical anual preocupa-se com o quantitativo referente ao ranking nacional, indissociável as prerrogativas do Saerjinho.

7 - Tais perspectivas e orientações foram geradas na Conferência de Jomtien (1990), e mais tarde publicadas no

"Relatório Delors" (1996), que através do discurso da "Educação Para Todos" afeiçoa-se uma mentalidade presa às necessidades da flexibilidade e da performatividade (Tura; Marcondes, 2011, p. 105; Ball, 2010).

8 - Para Pochmann (2012) o cenário atual de inserção no mercado de trabalho está relacionado a postergação da juventude na aquisição do primeiro emprego, combinado a continuidade do ciclo educacional ao longo da vida economia do conhecimento. Apesar de não salientar que tal contemplação é salutar a camadas socioeconômicas específicas, releva as dificuldades para a população jovem reproduzir lógicas comuns a gerações anteriores.

9 - Segundo Varsopollo (2005) e Alves (2011), o trabalho pós-fordista delega novas formas inerentes à 
imaterialidade do processo de produção, alterando obviamente, o controle sobre o trabalhador, deslocando-se para a totalidade cotidiana do mesmo, através de imperativos subjetivos - ratificando a nova ética sociometabólica do capital, impondo a adaptação das demandas do mercado à reprodução cotidiana do trabalhador.

10 - Segundo o Instituto Brasileiro de Geografia e Estatística (IBGE, 2011), o número de desocupados no Estado do Rio de Janeiro ao longo da década passada obteve acréscimo de aproximadamente 10\% entre os trabalhadores com até sete anos de instrução no mercado formal, enquanto os empregos com carteira assinada chegaram a 42\%, apresentando um acréscimo de aproximadamente 10\% em comparação ao ano de 1991.

11 - A Teoria do Capital Humano tem como um de seus precursores o economista Theodore Schultz, que em sua obra $O$ valor econômico da educação (1962), defende a instrução como um investimento em habilidades e conhecimentos que potencializará os sujeitos à ampliação da renda, e portanto, logra a educação uma das condições básicas para o crescimento econômico não só no presente (Frigotto, 2010). Sobre isso, Saviani (1986) considera, para além das questões econômicas, que a escola teria um papel messiânico diante do senso comum, ocultando as intencionalidades do capital para o desenvolvimento desigual.

12 - Expressão utilizada no manual de orientações.

13 - Tal observação potencializa analiticamente uma concepção interdisciplinar funcionalista, sob a ótica da pedagogia crítica, segundo de Santomé (1998, p. 28); pois o mesmo propicia possivelmente o ocultamento, ou pouca profundidade científica a conceitos e categoriais específicas das disciplinas citadas, que são indissociáveis do cotidiano; além da ausência de questões mais complexas, que produzidas em diversas escalas interrelacionadas, se materializam na dinâmica espaço-tempo dos estudantes, como veremos adiante no tratamento oferecido a categoria trabalho.

14 - Outra observação a ser realizada é a quantidade de habilidades e competências para cada bimestre, que segundo algumas considerações (Young, 2011), poderia recair na pressão conteudística sobre os professores, principalmente para a conclusão dos conteúdos, como orientado pela resolução 4669/11.

15 - É digno de nota comentar que o Plano Nacional do Livro Didático (PNLD) para o Ensino Médio da Educação de Jovens e Adultos ocorreu pela primeira vez no ano passado - 2014. E, portanto, o manual aqui analisado não passou pela avaliação do Ministério da Educação.

16 -. http://projetoseeduc.cecierj.edu.br/principal/novaeja/modulo03/Miolo_Ciencias_Humanas_Mod03_Vol01_ Nova_ejaAluno.pdf

17 - O mesmo é descrito por Alves (2011, p. 64) como atributo qualitativo da nova morfologia da relação capital-trabalho, através do processo de "desespecialização" do trabalho, logrando aos trabalhadores o despojo de qualquer identidade - na ótica fordista-taylorista -, ou significado concreto de sua prática no âmbito produtivo. Portanto, a flexibilidade torna-se ao mesmo tempo um conceito que determina a amplitude necessária à capacitação do trabalhador, desidentificado com uma função apenas, e dessa maneira incorporada de uma polivalência vazia. 


\section{BIBLIOGRAFIA}

ALVES, Giovanni. Trabalho e Subjetividade - o espírito do toyotismo na era do capitalismo manipulatório. São Paulo: Boitempo, 2011.

ANDRADE, Rodrigo Coutinho; FRANÇA FILHO, Astrogildo Luiz de. Velhas garrafas em rótulos novos: a continuidade do Brasil que se ensina no Currículo Mínimo da SEEDUC-RJ.In: $12^{\circ}$ Encontro Nacional de Práticas de Ensino de Geografia, 2013, João Pessoa -Paraíba. Anais ... João Pessoa, PB: Enpeg, 2013.

ANTUNES, Ricardo. O caracol e sua concha: ensaios sobre a nova morfologia do trabalho. São Paulo: Boitempo, 2005.

. Adeus ao trabalho? Ensaio sobre as metamorfoses e a centralidade do Mundo do

Trabalho. 15. ed. São Paulo: Cortez, 2011.

ARROYO, Miguel G. As relações sociais na escola e a formação do trabalhador. In: FERRETI, C. J.; SILVA JÚNIOR, J. dos R. (orgs.). Trabalho, formação e currículo: para onde vai a escola? São Paulo: Xamã, 1999.

BALL, Stephen J. Performatividades e fabricações na economia educacional: rumo a uma sociedade performativa. Educação e Realidade. Vol. 35, n. 2, p. 37-55, maio/ago de 2010.

BERNSTEIN, Basil. A pedagogização do conhecimento: estudos sobre recontextualização. Cadernos de Pesquisa, n. 120, p. 75-110, novembro/2003.

BRESSER-PEREIRA, Luiz Carlos. Da administração pública burocrática à gerencial. Revista do Serviço Público, 47(1) janeiro1996.

CASTELLAR, S.; VILHENHA, J. Ensino de Geografia. São Paulo: Cengage Learning, 2011.

CIAVATTA, M.; RUMMERT, S. M. As implicações políticas e pedagógicas do currículo na educação de jovens e adultos integrada à educação profissional. Educação e Sociedade. Campinas, v. 31, n. 111, p. 461-480, abr.-jun. 2010.

DALE, Roger. Globalização e educação: demonstrando a existência de uma cultura educacional mundial comum" ou localizando uma "agenda globalmente estruturada para a educação? Educação $e$ Sociedade. Vol. 25, n. 87, maio-agosto, 2004, pp. 423-460.

FRIEDMAN, Milton. Capitalismo e Liberdade. São Paulo: nova cultural, 1985.

FRIGOTTO, Gaudêncio. Educação e a crise do capitalismo real. 6a. ed. São Paulo: Cortez Editora, 2010.

FRIGOTTO, G.; CIAVATTA, M. Educação Básica no Brasil na década de 1990: subordinação ativa e consentida à lógica do mercado. Educação e Sociedade. Campinas, vol. 24, n. 82, p. 93-130, abril 2003.

GOVERNO DO ESTADO DO RIO DE JANEIRO. SECRETARIA DE ESTADO DE EDUCAÇÃO DO RIO DE JANEIRO. Bonificação por resultados: tudo que você precisa saber sobre bonificação por resultados da SEEDUC-RJ. 26 p. s/d(a). Ciências Humanas e suas Tecnologias - Módulo 03. 376 p. s/d(b).

. Resolução 4669/2011. Imprensa Oficial: DOERJ, 07/01/2011.

. Manual de Orientações - Nova Eja. 24 p. 2013a.

Currículo Mínimo. 16 p. 2013 b.

HARVEY, David. A condição Pós-moderna. São Paulo: Loyola, 1993.

O enigma do capital e as crises do capitalismo. São Paulo: Boitempo, 2011.

LIPIETZ, A.; LEBORGNE, D. O Pós-fordismo e o seu espaço. Revista Espaço \& Debates, n. 25, 1988.

LOJKINE, Jean. A revolução informacional. São Paulo: Cortez, 1995.

MARX, Karl. O Capital: crítica da economia política. Rio de Janeiro: Civilização Brasileira, 1999.

MATTOS, Valéria. Pós-graduação em tempos de precarização do trabalho. São Paulo: Xamã, 2011.

MÉSZÀROS, István. A crise estrutural do capital. São Paulo: Boitempo, 2002.

A educação para além do capital. São Paulo: Boitempo, 2005.

MOREIRA, Ruy. Pensar e ser em Geografia. São Paulo: Contexto, 2010.

O Discurso do Avesso - Para a Crítica da Geografia que se Ensina. Rio de Janeiro: Editora

Dois Pontos, 1989.

OLIVEIRA, Francisco de. Crítica à razão dualista: o ornitorrinco. São Paulo: Boitempo, 2013.

PARO, Vitor Henrique. Implicações do caráter público da educação para a administração da escola 
pública. Educação e Pesquisa. São Paulo. V. 28, n. 2, p. 11-23. Jul/dez, 2002.

. A teoria do valor em Marx e a educação. São Paulo: Cortez, 2006.

Parem de preparar para o trabalho!!! Reflexões acerca dos efeitos do neoliberalismo sobre a gestão e o papel da escola básica. In: Seminário Trabalho, Formação e Currículo. 1988, PUC/São Paulo.

POCHMMAN, Marcio. Trabalho e Formação. Educação e Realidade. Porto Alegre, v. 37, n. 2, p. 491-508, maio/ago. 2012.

.Brasil: segunda grande transformação no trabalho? Estudos Avançados, n. 28, 2014.

PONTUSCHKA, N. N.; PAGANELLI, T. I.; CACETE, N. H. Para Ensinar e aprender Geografia. São Paulo: Cortez, 2007.

RUMMERT, Sonia M. A modernização conservadora como marca da educação de jovens e adultos trabalhadores no Brasil. In: Políticas de formação de jovens e adultos no Brasil e em Portugal. RUMMERT, S. M. et. al. (orgs.). Niterói: Editora da UFF, 2009.

SANTOMÉ, Jurjo Torres. Globalização e Interdisciplinaridade - o Currículo Integrado. Porto Alegre: Artmed, 1998.

SANTOS, Milton. O espaço do cidadão. 7. ed. São Paulo: EdUSP, 2012.

SANTOS, Vinicius O. Trabalho imaterial e teoria do valor em Marx: semelhanças ocultas e nexos necessários. São Paulo: Expressão popular, 2013.

SANTOS, Aparecida de F. Tiradentes dos. Desigualdade social e desigualdade escolar conhecimento e poder em Paulo Freire e Gramsci. Rio de Janeiro: Vozes, 2000.

SAVIANI, Demerval. Escola e democracia. São Paulo: Editora Cortez, 1986.

SENNETT, Richard. A corrosão do caráter: as consequências pessoais do trabalho no novo capitalismo. 17. ed. Rio de Janeiro: Record, 2012.

SILVA, Tomaz T. da. Educação, trabalho e currículo na era do pós-trabalho e da pós-política. In: FERRETI, C. J.; SILVA JÚNIOR, J. dos R. (orgs.). Trabalho, formação e currículo: para onde vai a escola? São Paulo: Xamã, 1999.

SOUZA, José dos S. Trabalho, qualificação, ciência e tecnologia no mundo contemporâneo: fundamentos teóricos para uma análise da política de educação profissional. In: SANTOS, J. dos S. Trabalho, qualificação e políticas públicas. Rio de Janeiro: 7letras, 2011.

TURA, Maria de L. Rangel; MARCONDES, Maria I. O mito do fracasso escolar e o fracasso da aprovação automática. Cadernos de Educação. Pelotas. Vol. 38, p. 95-118. Jan/abr, 2009.

VASAPOLLO, Luciano. O conflito Capital-Trabalho na competição global. Revista Espaço Acadêmico. Ano III, n. 25 - junho de 2003.

O trabalho atípico e a precariedade. São Paulo: Expressão Popular, 2005.

YOUNG, Michael. O futuro da educação em uma sociedade do conhecimento: o argumento radical em defesa de um currículo centrado em disciplinas. Revista Brasileira de Educação. Rio de Janeiro: ANPEd; Autores Associados, v.16, n.48, set./dez. 2011. 